\title{
Justified Believing: Avoiding the Paradox
}

\author{
Gregory W. Dawes \\ Department of Philosophy \\ University of Otago \\ Dunedin
}

New Zealand 9054

This is a pre-publication copy of a chapter published in Rationis Defensor: Essays in Honour of Colin Cheyne, edited by James Maclaurin, 11-21. Studies in History and Philosophy of Science 28. Dordrecht: Springer, 2012. Citations should refer to the published copy, available at http://link.springer.com/chapter/10.1007\%2F978-94-0073983-3 2

$$
\text { () } \odot \text { ( }
$$

This draft paper is licensed under the Creative Commons Attribution-Share Alike 3.o License. You are free to cite this material provided you attribute it to its author; you may also make copies, but you must include the author's name and a copy of this licence. http://creativecommons.org/licenses/by-sa/3.0/ 


\title{
Justified Believing: Avoiding the Paradox
}

\begin{abstract}
Colin Cheyne has argued that under certain circumstances an internalist or deontological theory of epistemic justification will give rise to a paradox. The paradox, he argues, arises when a principle of epistemic justification is both justifiably believed (in terms of the theory) and false. To avoid this paradox, Cheyne recommends abandoning the principle of justification-transference, which states that acts of believing made on the basis of a justifiably-believed principle are themselves justified. Since such a principle seems essential to any internalist theory of justified believing, internalist theories may also need to be abandoned. I argue that while some theories of epistemic justification may indeed give rise to this paradox, an internalist or deontological theory of subjective justification will avoid it. The reason for this is that a false principle of justified believing does not render acts of believing subjectively unjustified, provided that the agent does not realize that the principle is false.
\end{abstract}

Colin Cheyne has recently outlined what appears to be a reductio ad absurdum of a traditional account of justified belief. He begins from three apparently uncontroversial ideas, which he sets out as follows (Cheyne, 2009, p. 278).

(1) There are circumstances in which an agent is justified in believing a falsehood.

(2) There are circumstances in which an agent is justified in believing a principle of epistemic justification.

(3) Beliefs acquired in compliance with a justifiably-believed epistemic principle are justified.

Cheyne shows that there are circumstances in which these three ideas can lead to a paradox, in which a given belief is simultaneously justified and unjustified. In what circumstances does the paradox arise and can we avoid it? 


\section{Cheyne's Alleged Paradox}

The paradox arises when, in accord with principle (1), an agent forms a justified false belief. But this belief is not merely a false belief; in accord with principle (2), it is a belief in a false principle of epistemic justification. Cheyne's example is that of Albert, who forms a justified but false belief "that reading tea-leaves is a reliable method for acquiring true beliefs" (p. 287). Albert then uses this false epistemic principle to form new beliefs, which I shall call "derivative beliefs." He forms these new beliefs by reading tea-leaves. Principle (3) - that of "justification-transference" - says that these derivative beliefs will themselves be justified (p. 285). But since the tea-leafreading principle is a false principle of epistemic justification, these same beliefs will be unjustified. Hence the paradox, which seems to be a reductio ad absurdum of at least one traditional idea of justified belief.

Let me attempt to spell this out a little more formally. In the scenario Cheyne posits Albert justifiably believes that for every act of believing, if it is performed on the basis of reading tea-leaves, it is a justified act of believing. More generally,

(1) A subject $S$ justifiably believes that for every act of believing $p$ performed under circumstances $C$, that act of believing is justified.

Having justifiably believed in the tea-leaf-reading epistemic principle, Albert then forms a derivative belief: one formed by reading tea-leaves. Let's say it is a belief that he will inherit money next week. We have already accepted, for the sake of the argument, a second principle, that of justification-transference (p.2):

(2) Beliefs acquired in compliance with a justifiably-believed epistemic principle are justified.

From principles (1) and (2), it follows that the subject's belief that he will inherit money next week is justified.

In fact, however, Albert has justifiably but mistakenly formed this belief in the doxastic value of reading tea-leaves. Acts of believing performed on the basis of reading tea-leaves are not justified, even though Albert justifiably believes that they are. More generally,

(3) For every act of believing $p$ performed under circumstances $C$, that act of believing is unjustified. ${ }^{1}$

1 The assumption here is that justification has just two possible truth-values, so that what is not justified is unjustified. Alvin Goldman (1993: 274-75) 
From principle (3), it follows that Albert's belief that he will inherit money is unjustified. So the three principles together entail that his belief is both justified and unjustified. This is, as I understand it, Cheyne's paradox. ${ }^{2}$

Cheyne's argument suggests that in order to avoid this paradox we need to abandon one of his three initial principles. The obvious principle to abandon is the principle of justification-transference. The externalist, he argues, might be able to abandon this principle, since for the externalist what is happening in the agent's mind is irrelevant to the question of justification. It is the reliability or unreliability of the process giving rise to the belief that matters. On an externalist view, therefore, "the unreliability of tea-leaf reading trumps Albert's justified belief that tea-leaf reading is reliable" ( $p$. $287)$. But it seems that no similar way out is available to the internalist, at least one who holds to a deontological account of justification. If justification is a matter of "fulfilling one's epistemic duties or responsibilities" (p. 289), then Albert would be acting irresponsibly if he did not regard his derivative beliefs as justified. After all, it would seem irresponsible to form a justified belief in an epistemic principle - even a tea-leaf-reading principle - and then ignore it when forming one's beliefs. So it seems we must abandon deontological accounts of justification.

suggests the possibility of a third, neutral category - that of non-justified but not necessarily unjustified beliefs - but I shall not pursue that possibility here.

2 Throughout this paper, I have understood the falsity of the principle of epistemic justification to be objective falsity. In a recent conversation, Cheyne has suggested that the falsity in his scenario should be thought of as falsity according to the theory of justification being employed, rather than falsity simpliciter. But on this rather different assumption, my argument would still go through. To anticipate, what I am arguing is that an agent could be subjectively justified in accepting beliefs on the basis of a false principle of epistemic justification principle, provided that she does not realize that it is false. But this can be easily reworded to accommodate Colin's suggestion: an agent could be subjectively justified in accepting beliefs on the basis of a principle of epistemic justification that is inconsistent with another principle she holds, provided that she does not realize that it is inconsistent. In neither case does a paradox arise. 
Can we avoid this conclusion? There is, as one might expect, nothing wrong with Cheyne's logic here. But what I want to argue is that there is at least one version of an internalist account of justified believing that avoids this paradox. Moreover, the account that can avoid the paradox is precisely the one that Cheyne believes needs to be abandoned, namely a deontological account. In the case of a nondeontological account, the paradox can be avoided (as Cheyne suggests) by abandoning the principle of justification-transference. But this is, I shall argue, a conclusion that any internalist could accept.

\section{Two Internalist Conceptions of Justification}

I am understanding internalism to be the view that the essential factors that make a belief justified or unjustified have to do with the mental state of the agent. Let me begin by offering, for the sake of the argument, one version of such a view. I shall begin by describing the mental states relevant to justification as the agent's reasons for believing. 3 I wish to leave open what form those reasons might take. They may consist, for instance, of other beliefs from which the content of her new belief can be inferred. Or they may consist of particular doxastic experiences, such as those of memory or sense perception. The internalist, on my view, holds that for an act of believing to be justified, these two conditions must be fulfilled.

(a) The agent's reasons for believing must be matters of which she is aware.

(b) It must be the case that she would, on reflection, consider these to be adequate grounds for her belief. 4

3 By "reasons for believing" I mean those factors that are the basis on which the agent believes. It is not easy to define this basing relation (see Korcz, 2010), but very often a causal account seems appropriate. An agent's reasons for believing are those factors that are bringing about (or sustaining) her belief.

4 Any attempt to articulate an internalist view will be controversial. My view assumes that for justified believing the agent must be aware of those factors - other beliefs or doxastic experiences - that are her reasons for believing. But she need not have formed any belief about (a) the fact that they are her reasons for believing or (b) their adequacy as reasons. What is required for 
The key question then is: Is the state of affairs represented by these two conditions a sufficient or merely a necessary condition of justification (Kvanvig 1984: 72)? Each of these options will give rise to a distinctive sense of what it means for a belief to be justified: the first subjective and the second objective (Pollock 1979: 109-10).

\subsection{Subjectively Justified Acts of Believing}

A subjective account of justified believing holds that conditions (1) and (2) are sufficient for justification. An act of believing is justified if the agent has (a) done all that she ought to do to examine the grounds of her belief and (b) would (on reflection) consider these to be adequate grounds.

The "ought" here indicates that this is what is customarily called a deontological view. But the term "deontological" may be misleading, since the "ought" here need not be thought of as ethical. Richard Feldman, for instance, suggests it is best regarded as a "role ought" (Feldman 2000: 676). ("If you are a competent pianist, you ought to be able to play Beethoven's Moonlight Sonata.") On this view, there are ways in which you ought to act, in your role as a knower. Alternatively, one could regard it as the kind of "ought" that is characteristic of practical reason. ("If you want to become a competent pianist, you ought to practise daily.") On this view, if you want to obtain knowledge, this is how you ought to act in order to attain your goal. But in precisely what sense subjective justification is deontological is not a question I need discuss here.

This kind of justification is subjective in several senses. One of these is that what it entails is person- and context-relative. If I hear rumours about possible side-effects of a vaccine, how I ought to respond will depend on who I am. If I am a doctor, it may be that I ought to examine the evidence more carefully than if I am merely a

\footnotetext{
justification is that she would, on reflection, consider them to be adequate reasons. (The "adequacy" here is, of course, epistemic: an adequate reason is such that if her belief that $p$ is true, she can be said to know $p$.) By taking this line, I hope to avoid the notorious infinite regress problem (Ruloff, 2009, 144-45). But it also seems to me that a person who has long held a justified belief could say, quite intelligibly, "Yes, my belief that $p$ is the reason I believe that $q$, and it seems to me a good reason, even though I've never reflected on its evidential force before."
} 
curious member of the public. (The "ought" in this context does have an ethical dimension.) What subjective justification entails is also person- and context-relative in another sense: whether I am acting rationally in forming this belief will depend on the methods of reasoning that are available to me. A person trained in medicine will be better placed to appraise the evidence regarding the vaccine than a person without such training, and would be falling short of her epistemic obligations if she did not make use of these skills. And a person living in the twenty-first century will have methods of assessment available to her that were not available in medieval Europe.

But the key point here is that an act of believing is subjectively justified if, at the end of this process, the agent would (on reflection) consider her reasons for believing to be adequate reasons. This judgement does not need to be correct. Her belief regarding the available reasons would be sufficient, on this view, for justification. It would remain so even if she has made some honest error of reasoning or if the mechanism that gives rise to her belief is not, in fact, as reliable as she believes it to be. The intuition behind such a notion is that one does not cease to be a rational agent as a result of making a (non-obvious) mistake regarding the available evidence. To accommodate such an intuition, some notion of subjective justification seems required.

\subsection{Objectively Justified Acts of Believing}

There are times, however, when our (internalist) question about justification is a different one. We might agree that a person is subjectively justified in forming a belief, but still want to know if her judgements regarding her reasons for belief are correct. In other words, we want to know if she has formed her beliefs in ways that are objectively appropriate (Henderson and Horgan 2001: 227). This is not the same as asking if what she believes is true, since it is (as we shall see) possible to make a correct judgement on the basis of the available evidence and still form a false belief (see p.13). Nor is it a deontological question, since it is not answered by the observation that the agent has acted as she ought to in forming the belief. She may, for instance, have examined the evidence to the best of her ability and still made an error of judgement. The question regarding 
objective justification has to do with what the evidence available to the agent actually warrants.

It follows that the answer to this question will not be person- and context-relative. Admittedly, our starting point in answering it will be person- and context-relative, since we will start with the evidence that was available to this agent at the time she formed her beliefs. But given that evidence, the justifying relation, however that is conceived, will be entirely objective. If the evidence available to the agent really does support the act of believing - whether by deductive, inductive, or abductive reasoning, or in some other way - the act of believing is objectively justified.

Because this sense of "justified believing" has to do with the objective conditions under which something is believed, it may appear to be an externalist notion. After all, the validity or soundness of an argument is an objective fact: it does not depend on what the subject believes about it. The similarity with externalism will be particularly striking when we are dealing with a belief that arises not from a process of reasoning, but spontaneously, as a result of some mechanism (such as sense perception). The reliability or unreliability of the mechanism is also a fact that is independent of what we believe about it. But even in these circumstances, objective justification can still be considered an internalist idea. It is not, for example, the mere fact that the mechanism happens to be reliable that makes the belief justified. The agent must be aware of this mechanism and her other beliefs must be such that she would, on reflection, consider it to be reliable. To ask if her confidence in this mechanism is objectively justified is to ask if her other beliefs really do support her conviction that it is reliable.

Here's another way of making the point. I suggested earlier than on an internalist account, there are two conditions that need to be met for a justified act of believing.

(a) The agent's reasons for believing must be matters of which she is aware.

(b) It must be the case that she would, on reflection, consider these to be adequate grounds for her belief.

If what we are interested in is subjective justification, then these conditions are sufficient for justification. But if what we are 
interested in is objective justification, then they are merely necessary conditions. An agent's act of believing could meet both of these conditions, but still fail to be objectively justified, since the evidence on the basis of which she is believing does not, in fact, support her belief, even though she would (on reflection) consider it to do so.

Here are a couple of examples. Galileo Galilei may have been acting rationally - he may have been subjectively justified - in holding to his particular theory of the tides. But he might also have made some poor judgements in this respect: it may be that even the evidence available to him did not in fact support his theory. A contemporary Christian may be subjectively justified in holding to her Christian faith, if she has done all she ought to do to examine the evidence and her belief seems to her to be warranted (Plantinga 2000: 252-53). But she may still be mistaken in making these judgements. Even if she is subjectively justified, we can still ask if the facts or experiences that she takes to be evidence of the truth of her faith really do constitute adequate reasons for believing. 5

\subsection{Related Distinctions}

Before continuing my argument, I should note two distinctions that could be confused with the one I have just made. While related to my distinction, they are not identical with it.

The first is one that Cheyne himself employs, distinguishing (as we have seen) between the act of believing and the content of belief. His argument chooses (rightly) to focus on the act of believing (p.279). But the distinction I have just made - between a subjective and an objective sense of "justified believing" - is not identical with this. I, too, wish to focus on the act of believing, the question being (on an internalist account) whether an agent has adequate reasons for a particular act of believing. But this question, as I hope my discussion has shown, can be formulated either subjectively or objectively. It can be a question about whether the agent has reasons that she would (on reflection) consider adequate reasons or a question about whether she has what really are adequate reasons. She may believe, for instance, that inference to the best explanation

5 This is a question that Alvin Plantinga, in developing his Reformed Epistemology, entirely neglects. 
(IBE) warrants belief, and thus be subjectively justified in believing the best available explanation of some fact. Or she may believe that sense perception, in these particular circumstances, is reliable, and thus be subjectively justified in accepting the evidence of her senses. But we can still ask if IBE really does warrant belief or if sense perception really is reliable in these circumstances. So it is possible that the subject's subjectively justified act of believing may not be objectively justified.

A second distinction, which is closer to mine but still not identical with it, is that between propositional and doxastic justification. In a recent article, Colin Ruloff sets it out as follows:

Propositional justification obtains when an agent $S$ s total available evidence makes a proposition $p$ likely to be true - even if $S$ does not believe $p$ or $S$ believes $p$ for the wrong reason. Doxastic justification, by contrast, obtains when a proposition $p$ has propositional justification for $S$ and when $S$ believes $p$ on the basis of justifying evidence or grounds. Doxastic justification ..., thus, requires that $S$ 's belief that $p$ be appropriately related to $S$ 's evidence or grounds. (Ruloff, 2009, 134)

Propositional justification resembles objectively justified acts of believing since it, too, has to do with an objective relation between evidence and belief. But in common with Cheyne, I am focusing not on the proposition believed, but on the act of believing, so the justification with which I am concerned is doxastic justification. My distinction between subjectively and objectively justified acts of believing has to do with different ways of conceptualising the "appropriate relation" between an agent's act of believing $p$ and the grounds on which she believes $p$. On a subjective account, an agent's act of believing is justified if it would (on reflection) seem to her that an appropriate relation exists. On an objective account, an agent's act of believing is justified only if that relation really is appropriate: if the reasons on the basis of which she believes are, in fact, adequate reasons.

\section{Internalism and the Paradox}

Armed with this distinction, I can now return to Cheyne's paradox. What I hope to show is that no paradox arises in the case of a 
subjective (or deontological) accounts of justification. A paradox might arise in the case of an objective account of justification, but this is a fact which an internalist could easily accept.

\subsection{Subjective (Deontological) Justification}

Let's begin with an example that may seem a little more plausible than Cheyne's tea-leaf reading example. Let's say that Mary believes in a principle (let's call it $R$ ) which states that one is justified in believing whatever the Pope, as Bishop of Rome, teaches. Mary would, on reflection, consider that the reasons on the basis of which she believes this principle are adequate reasons. She is, therefore, subjectively justified in believing the following proposition:

(R) For any proposition $p$, simply by virtue of the fact that the Pope has declared $p$ to be true, then one is justified in believing $p$.

Mary would then consider that she had adequate reasons to believe a particular papal teaching - such as the idea that the Blessed Virgin Mary was assumed bodily into heaven - the adequate reason being precisely principle $R$. So her belief in the doctrine taught by the Pope is also subjectively justified. Given a principle of justificationtransference $(J T)$, this seems correct.

(JT) Beliefs acquired in compliance with a justifiably-believed epistemic principle are justified.

Let's now say, for the sake of the argument, that $R$ is false.

(not-R): For any proposition $p$, it is not the case that simply by virtue of the fact that the Pope has declared $p$ to be true, then one is justified in believing $p$.

Cheyne's argument, as I understand it, is that this gives rise to a paradox. If Mary is subjectively justified in believing $R$, even though $R$ is false, then by $J T$ she is also justified in believing $p$, a belief taught by the Pope, simply by virtue of the fact that he teaches it. But according to not- $R$, she is not justified in believing $p$, simply by virtue of the fact that the Pope teaches it.

The problem with this argument is that it fails to distinguish the two senses of justified believing that I have attempted to spell out. Given that Mary is subjectively justified in accepting $R$ then - given $J T$ - she is also subjectively justified in accepting a particular papal 
teaching. What not- $R$ shows is that she is not objectively justifed in accepting that teaching. But there seems no reason to assume that a person cannot be both subjectively unjustified and objectively unjus tified. She has simply made a mistake about the proper way to form beliefs.

\subsection{Objective Justification}

But what about objective justification? We have seen that the falsity of a principle of justification leads to no paradox in the situation in which I am subjectively justified in believing that principle. But would the paradox arise in the circumstances in which I am objectively justified in believing a false principle of justification?

Could this situation ever arise? It's difficult to know. Let's look again at the situation of Mary. Mary has been reading a learned Roman Catholic apologist. This apologist has produced valid arguments for principle $R$. Those arguments might state, for example, that Jesus appointed St Peter as the rock on which the church was to be built (Matt 16:18) and that the Bishops of Rome inherited his office. From these two premises he deduces that in matters of faith the Popes will never be in error and that principle $R$ is therefore justified. Papal authority is, in effect, a reliable mechanism producing true beliefs. Let's grant, for the moment, the logic of the apologist's argument. But let's also assume that one of the premises is false. It may be, for instance, that the words attributed to Jesus in the Gospel of Matthew are a fiction or that the Popes did not in fact inherit the office given to St Peter. Let's assume, too, as we did before, that principle $R$ is false. Would Mary be objectively justified in believing $R$ ?

The answer one gives to this question will depend on how one answers a second question: Could a false belief taken as evidence constitute objective justification for an act of believing? If, for example, Mary falsely believes that the premises of the apologist's arguments are true, does the validity of his argument mean that her belief is objectively justified? It may be that a false belief cannot objectively justified another belief (Lehrer 1974: 213-14), even though it could subjectively justify it. This seems plausible. If that which (objectively) justifies a belief is the fact that one could construct a deductive argument leading from evidence to proposition 
believed, then it is not sufficient that such an argument be valid. It must also be sound: its premises must be true. If this is the case, then Mary's belief in $R$ is not objectively justified, no matter what she believes about it. But if Mary's belief in $R$ is not objectively justified, then no paradox arises.

Are there other circumstances in which I might be objectively justified in believing a false principle of justification? I have suggested that my act of believing cannot be objectively justified when the evidence on which I base my belief is false. But what if the evidence on which I base my belief is true but incomplete? In these circumstances, it seems, I could be objectively justified in holding a false belief. Given the evidence available to me today, I am objectively justified in believing that the butler was responsible for the murder. But new evidence might turn up tomorrow that exonerates the butler and makes it clear the maid was responsible. In a similar way, it is conceivable that the arguments in favour of a particular belief-forming policy (such as $R$ ) may be sound. But if they are inductive or abductive arguments - arguments in which the premises can be true but the conclusion false - then new evidence could still indicate that the conclusion they supported was the wrong one.

Only in these circumstances - in which I am objectively justified in accepting a false principle of justification - would an internalist need to confront Cheyne's paradox. ${ }^{6}$ Let's say that Mary was objectively justified in believing the (false) principle $R$.

(R) For any proposition $p$, simply by virtue of the fact that the Pope has declared $p$ to be true, then one is justified in believing $p$.

6 In an earlier draft of this paper, I distinguished four cases (rather than merely two): (a) subjectively justified belief in a false principle of subjective justification, (b) subjectively justified belief in a false principle of objective justification, (c) objectively justified belief in a false principle of subjective justification, and (d) objectively justified belief in a false principle of objective justification. While this did exhaust the alternatives, I now believe it to have been unnecessarily confusing. But for the record, the case I am here considering is most accurately characterized as an example of (d). None of the others could rise to a paradox, since there is no reason why a belief cannot be subjectively justified but objectively unjustified or objectively justified but subjectively unjustified. 
Let's accept, too, the principle of justification transference, JT.

(JT) Beliefs acquired in compliance with a justifiably-believed epistemic principle are justified.

Mary is then objectively justified in forming a belief that $p$, on the grounds that the Pope declares $p$ to be true. But ex hypothesi, $\mathrm{R}$ is false.

(not-R): For any proposition $p$, it is not the case that simply by virtue of the fact that the Pope has declared $p$ to be true, then one is justified in believing $p$.

It follows that Mary's belief that $p$ is objectively unjustified. So the same belief would be both objectively justified and objectively unjustified, quod est absurdum.

In these circumstances, and in these circumstances alone, Cheyne would be right. When faced with an objectively justified false belief, we cannot maintain the principle of justification-transference. Even if Mary is objectively justified in believing the false principle $R$, this does not mean that the beliefs she forms on the basis of $R$ are objectively justified. I see no reason, however, why an internalist could not accept this conclusion, since the subjective (or deontological) sense of justified believing has emerged from this discussion unscathed.

\section{Conclusion}

At first sight, Cheyne's paradox looks like a reductio ad absurdum of a popular view of justified belief. It demands the surrender of a principle - that of justification-transference - that seems vital to a deontological view of epistemic justification. But on closer examination, we find that it is precisely the deontological view of justified believing that escapes the paradox and allows us to retain that principle. The reason for this turns out to be a simple one. It is that the falsity of a principle of epistemic justification does not render an act of believing that relies on this principle subjectively unjustified. It would do so only if the agent realized that the principle was, indeed, false, but ex hypothesi she does not. It follows that no paradox arises in the case of the subjective (or deontological) sense of justified belief. 
On the other hand, it may be that the falsity of a principle of epistemic justification renders an act of believing that relies on this principle objectively unjustified. If so, then the objective sense of justified believing will give rise to a paradox in the conditions that Cheyne outlines. It would follow that when we speak of justified believing in the objective sense, we will have to abandon the principle of justification-transference. But this is not a conclusion that should bother internalists, given that the deontological (subjective) use of this principle has been saved.

My conclusion, then, is that a deontological view of justified believing can survive Cheyne's criticism. This is not, however, to say that it can survive all criticisms. There remain powerful arguments against internalist accounts of justified believing. I have made no attempt to address such arguments, since this paper does not pretend to be a defence of epistemic internalism tout court. All I have attempted to do is to defeat one objection to an internalist view, understood in deontological terms. 


\section{References}

Cheyne, C. (2009) "A Paradox of Justified Believing." Ratio NS 12: 278290.

Feldman, R. (2000) "The Ethics of Belief." Philosophy and Phenomenological Research: 667-695.

Gettier, E. L. "Is Justified True Belief Knowledge?” Analysis: 121-123.

Goodman, Alvin. (1993) "Epistemic Folkways and Scientific Epistemology" Philosophical Issues 3: 271-285.

Henderson, D and T. E. Horgan. (2001) "Practicing Safe Epistemology." Philosophical Studies 102: 227-258.

Korcz, K. A. (2010) “The Epistemic Basing Relation." In The Stanford Encyclopedia of Philosophy (Spring 2010 Edition), edited by Edward N. Zalta <http://plato.stanford.edu/ar-chives/spr2010/entries/basingepistemic/>.

Kvanvig, J. L. (1984) Subjective Justification.” Mind 93: 71-84.

Lehrer, K. (1974) Knowledge. Oxford: Clarendon.

Plantinga, A. (2000) Warranted Christian Belief. York: Oxford University Press.

Pollock, J. L. (1979) "A Plethora of Epistemological Theories." In Justification and Knowledge: New Studies in Epistemologyedited by George S. Pappas, pp. 93-113. Philosophical Studies Series in Philosophy 17. Dordrecht: D. Reidel.

Ruloff, C. (2009) "Epistemic Supervenience and Internalism: A Trilemma." Theoria 75: 129-151. 